\title{
Investigation of Factors Influencing the Construction Safety of High-Speed Railway Stations Based on DEMATEL and ISM
}

\author{
Feng Lin $\mathbb{D},{ }^{1}$ Ping $W u\left(\mathbb{D},{ }^{2}\right.$ and Yidong $X u \mathbb{D}^{2}$ \\ ${ }^{1}$ School of Civil Engineering and Architecture, Jiangsu University of Science and Technology, Zhenjiang 212003, China \\ ${ }^{2}$ School of Civil Engineering and Architecture, NingboTech University, Ningbo 315100, China \\ Correspondence should be addressed to Ping Wu; wuping@nit.zju.edu.cn
}

Received 24 March 2021; Revised 17 May 2021; Accepted 30 May 2021; Published 12 June 2021

Academic Editor: Faming Huang

Copyright $\left({ }_{0} 2021\right.$ Feng Lin et al. This is an open access article distributed under the Creative Commons Attribution License, which permits unrestricted use, distribution, and reproduction in any medium, provided the original work is properly cited.

To explore the influencing factors and mutual influence mechanism of the construction safety of China's high-speed railway stations, this study takes the Hanghuang high-speed railway Fuyang station as the subject and studies 17 risk factors in 4 categories affecting construction safety based on system safety theory, and the interaction relationship and degree among the factors were analysed. Based on DEMATEL (Decision-making Trial and Evaluation Laboratory) and ISM (Interpretative Structural Modelling) methods, through a questionnaire survey, the logical relationship among the influencing factors is quantified. Then, the influencing degree, influenced degree, centrality, and causality of the influencing factors were calculated, and a multilevel hierarchical hybrid model is established to systematically analyse the influencing factors and the mechanism of high-speed railway station construction. The results show that the factors of construction safety risk are summarized as 3 main factors, 6 important factors, and 7 direct factors and personnel factors and management factors need to be controlled with emphasis. In addition, some measures are proposed. This research provides a theoretical basis and method for preventing accidents and improving the safety of high-speed railway station construction.

\section{Introduction}

With the rapid development of China's high-speed railway, its construction scale and speed of development have ranked first in the world [1]. At the same time, high-speed railway construction has been subject to safety issues due to its long production cycle, many working high above the ground in open air, complicated construction techniques, and many other factors. Construction safety accidents can cause serious casualties and heavy economic losses. According to the Ministry of Housing and Urban-Rural Development of the People's Republic of China, there were 4,100 construction and municipal engineering production safety accidents, with 5,011 deaths, in China (excluding Hong Kong, Macau, and Taiwan) from 2012 to 2018 [2]. Even in a developed country such as the United States, construction workers are twice as likely to be injured and have a death rate three and a half times higher than that of workers in production industries [3]. The death rate for construction workers in the UK is 5 times the average death rate of workers in the production industry [4]. Therefore, construction safety is a worldwide problem.

In the study of safety accidents, safety accident theories such as human error theory [5, 6], causal linkage theory [7], energy transfer theory $[8,9]$, and disturbance theory [10] have emerged successively. These theories analyse the relationship between safety accident factors and safety accidents from different perspectives and at different levels. With the recent increase in safety accident analysis in safety system engineering theory, system engineering technology was introduced into safety accident analysis in [11, 12]. However, previous studies have not examined the factors influencing safety accidents and safety accident causation, have not deepened the theory of accident causation, and have not identified safety accident factors for further systematic analysis from the perspective of the accidents.

There are two types of risk assessment research: qualitative and quantitative [13]. Qualitative research mainly 
includes the safety checklist method, expert consultation method, and prerisk analysis method [14-18]. Quantitative research mainly includes the analytic hierarchy process (AHP), operating condition risk evaluation method (LEC), neural network and support vector machine method (SVM), and fuzzy comprehensive evaluation (FCE) method [19-24]. However, the existing security risk assessment methods usually focus on a single indicator and do not consider the interactions or coupling of the indicators [25]. In fact, accidents are usually caused by a combination of many factors.

In the 1960s, Tavistock institute proposed the complex social technology system, referring to an industrial organization that is technology-intensive and capital-intensive and accumulates large amounts of energy [26]. With the increasing scale of a project, the increase in participants and stakeholder groups, and the expanded interaction between the project and the environment, it increasingly presents richer and more profound complex system characteristics and connotations [17]. The construction of a high-speed railway station has the characteristics of a typical complex social technology system: nonlinearity, emergence, feedback loops, and so forth [27]. From a system perspective, safety and actual accidents are emerging attributes of nonlinear interactions between different components of complex sociotechnical systems. Leveson established a system theory accident model (STAMP) based on the belief that an accident is an emergent phenomenon caused by the interaction of various elements in a complex system [28]. The lack of control behaviour that imposes constraints on these interactions will lead to accidents [29]. Security is a control problem that can be managed through the control structure embedded in the social technology system [29].

To determine how to control a complex system, we must first study the relationship of the factors. Existing methods for complex system factor analysis include ISM [30], DEMATEL [31], SEM [32], ANP [33], and complex network [34]. In this study, we combine DEMATEL and ISM to establish the relationship among factors affecting the construction safety of high-speed railway stations and establish a multilevel hierarchical structural model. Then, the importance of the influencing factors and their hierarchical relationship is determined, and the influence of these factors on high-speed railway station accidents is determined. Finally, some countermeasures are proposed. This study provides a theoretical basis and method for preventing accidents in the construction of high-speed railway stations.

\section{Methodology}

2.1. Extraction of Influencing Factors of Construction Safety. Various factors affecting the safety of complex systems interact. The influencing factors of high-speed railway station construction systems have an extraordinarily complex relationship and interactions, showing strong nonlinearity and reverse feeding. From 2012 to 2018, the types of accidents that frequently occurred in China's construction industry were falling from a height, structural collapse, lifting injuries, object attack, vehicle injuries, mechanical injuries, electric shock, poisoning and suffocation, fire and explosion, and other injuries. These accidents were the result of the interaction of multiple factors, including humans, machines, the environment, and management, rather than each case having a single cause.

Hamid believed that the cause of an accident is a multifactor phenomenon mainly involving worker negligence and bad attitudes towards safety, lack of safety devices, unskilled workers, etc. [35]. Haslam et al. investigated accidents in the UK and found that they were caused by workers, the working environment, equipment defects, and inadequate risk management [36]. When implementing safety control of complex systems based on control theory, the following are usually considered: human factors, organizational factors, management factors, and physical systems [37]. Du et al. studied an underground transportation system and concluded that it is a complex and enormous system with many factors affecting safety. The causes of accidents were defects in humans, machines, and the environment [38].

Through the analysis and summary of the relevant literature [35-42], in this research, we summarize four aspects of construction safety risk factors: human, mechanical, environmental, and management. In total, 17 risk factors are identified. The human aspect includes cognitive deficits, poor physical or mental health, and illegal operations. The mechanical aspect includes unreasonable equipment selection and layout, lack of equipment maintenance and overhaul, mechanical equipment failure, failure of construction monitoring equipment, and numerous large-scale equipment cross-operations. The management aspect includes imperfect safety management systems, inadequate safety disclosure, inadequate acceptance of key procedures, inadequate supervision of safety behaviours, inadequate safety protection measures, and errors in construction safety operational guidelines. The environmental aspect includes unforeseeable natural factors, complex hydrogeological environments, and complex construction site environments. The definitions are shown in Table 1.

\subsection{Risk Coupling Model Based on SD Model Causality} Diagram. In the construction safety risk of high-speed railway station, personnel factors, mechanical factors, environmental factors, and management factors interact and influence each other. The direct objects of management are human, machine, and environment; people have subjective initiative which will have an impact on things, environment, and management; mechanical equipment is affected by the environment, and the state of the equipment depends on personnel operation and reasonable and effective management; the environment has direct or indirect influence on people, things, and management. The interaction and mutual influence of human, material, environment, and management factors finally form human-material-environment-pipe coupling risk.

System Dynamics (SD) is the subject of information feedback systems. It is a combination of system theory, control theory, and information theory and provides a way to understand and solve system problems [43]. The SD 
TABLE 1: Construction safety risk factors and their interpretation.

\begin{tabular}{|c|c|}
\hline Factor & Interpretation \\
\hline Cognitive deficits R1 & $\begin{array}{c}\text { Managers and workers cannot recognize the possibility of safety accidents. Safety awareness is } \\
\text { a prerequisite for operational safety. }\end{array}$ \\
\hline Poor physical or mental health R2 & $\begin{array}{c}\text { Personality traits such as impulsiveness, emotional response, and carelessness. Physiological } \\
\text { conditions such as illness and fatigue. }\end{array}$ \\
\hline Illegal operations R3 & $\begin{array}{l}\text { During the construction process, the construction is not carried out according to the } \\
\text { construction safety operation guidelines. }\end{array}$ \\
\hline $\begin{array}{l}\text { Unreasonable equipment selection and } \\
\text { layout R4 }\end{array}$ & $\begin{array}{l}\text { The equipment model does not meet the nee } \\
\text { the construction, and the }\end{array}$ \\
\hline $\begin{array}{l}\text { Lack of equipment maintenance and } \\
\text { overhaul R5 }\end{array}$ & The equipment lacks daily maintenance and professional overhaul assessment. \\
\hline Mechanical failure R6 & $\begin{array}{l}\text { During the construction process, for various reasons, equipment malfunctions, stops } \\
\text { operating, and even causes chain accidents. }\end{array}$ \\
\hline Num & $\begin{array}{l}\text { The operations of large-scale mechanical } \\
\text { vehicl }\end{array}$ \\
\hline $\begin{array}{l}\text { Failure of construction monitoring } \\
\text { equipment R8 }\end{array}$ & $\begin{array}{r}\text { Construction monitoring such as foun } \\
\text { temperature monitoring, steel structure str } \\
\text { is perfor }\end{array}$ \\
\hline $\mathrm{U}$ & Earthquakes, $t$. \\
\hline ex hydrogeological environment & $\begin{array}{r}\text { The natural conditions of co } \\
\text { foun }\end{array}$ \\
\hline Complex construction site environments & $\begin{array}{l}\text { The combination of ventilation, lighting, temperature, humidity, noise, dust, and harmful } \\
\text { gases affects the physical and psychological conditions of construction workers. }\end{array}$ \\
\hline $\mathrm{R} 12$ & \\
\hline Incon & $\begin{array}{l}\text { The construction leader does not train the direct production workers on safety operational } \\
\text { rules and precautions before beginning the production operation. }\end{array}$ \\
\hline $\begin{array}{l}\text { Inadeq } \\
\mathrm{R} 14\end{array}$ & $\begin{array}{l}\text { As a necessary condition for the acceptance of a } \\
\text { effective quality control measure that high }\end{array}$ \\
\hline pervision of safety & $\begin{array}{l}\text { Leaders and management personnel at all levels do not sufficiently inspect and supervise the } \\
\text { workplace to correct improper behaviour and ensure the safety of production. }\end{array}$ \\
\hline Ina & $\begin{array}{c}\text { The arrangement of devices to prevent operators from generating risks in the production } \\
\text { process is not in place. }\end{array}$ \\
\hline Errors & $\begin{array}{l}\text { Operational sequences and operational instructions are not specified in the method and safety } \\
\text { regulations for technical operations. }\end{array}$ \\
\hline
\end{tabular}

cause-and-effect diagram theory is used to discuss and study the risk coupling relationship among various risk factors in the construction safety system of high-speed railway station. As shown in Figure 1, taking the starting point of management factors as an example, inadequate supervision of safety behaviours of management factor indirectly leads to unreasonable equipment selection and layout of mechanical factors, unreasonable equipment selection and layout indirectly lead to complex construction site environments of environmental factors, and complex construction site environments lead to poor physical or mental health of human factors. Taking the starting point of human factors as an example, illegal operations of human factors lead to mechanical failure of mechanical factors, mechanical failure leads to complex construction site environments of environmental factors, and complex construction site environments lead to inadequate supervision of safety behaviours of management factors.

2.3. Principles for the DEMATEL and ISM Method. DEMATEL, a method proposed by Bottle in 1971, uses matrix operations to calculate the direct or indirect causality and degree of influence of the elements. By using the causal diagram to determine the basic nature of the complex problem, the core problem is determined and solutions are suggested. DEMATEL can be used to divide factors into causal and influencing factors. In addition, by ranking or prioritizing causal factors, core problems can be solved quickly and effectively to improve performance [44]. ISM is a method developed by John N. Warfield in the United States in 1973 to analyse systems with numerous factors and complex and unclear structures based on graph theory and Boolean function. Multivariable, complex, and unstructured systems are transformed into multilevel explanatory structural models to show the influence paths and hierarchical structure of complex factors. ISM has the advantages of system operation, effectiveness, low data dependence, and clear handling of problems [45]. The DEMATEL-ISM hybrid has two advantages. First, the DEMATEL model can simplify the calculation process of the ISM model and provide convenience for the system. By directly adding thresholds $\lambda$ to DEMATEL's overall influence matrix, the reachable matrix required by ISM model is obtained. The process of ISM's adjacency matrix to reachable matrix is omitted. Second, the DEMATEL causality and centrality analysis can further use the unique advantages of the ISM model to clarify the structural hierarchical relationship. 


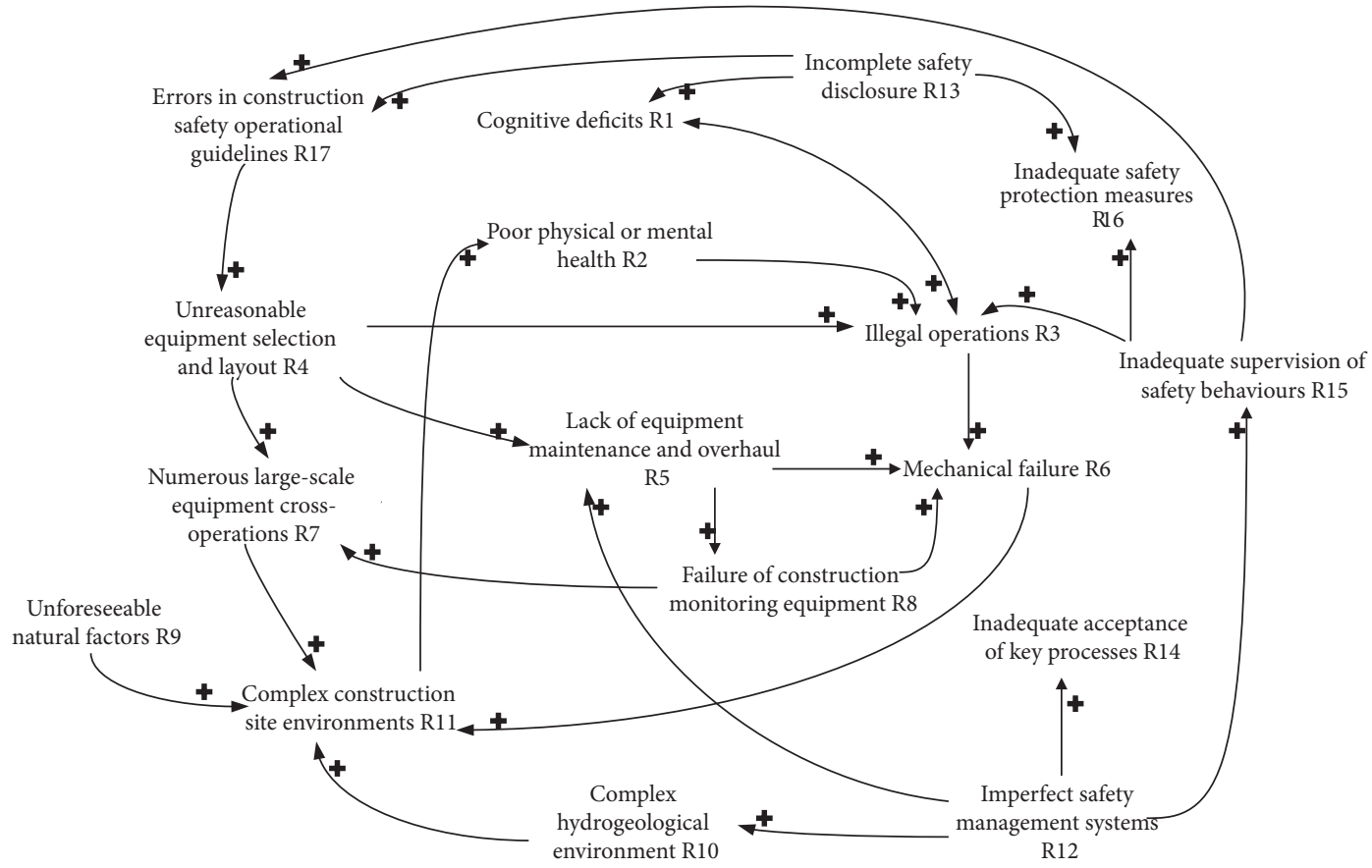

FIGURE 1: SD model causality diagram.

2.4. Modeling Process. The process of using DEMATEL-ISM model as shown in Figure 2 and the basic steps are as follows:

(1) Determine the construction safety risk factors $r_{1}, r_{2}$, $\ldots, \quad r_{n}, \quad r_{i} \in R(i=1,2, \ldots, n)$, where $n$ is the number of construction safety risk factors and $R$ is the total set of construction safety risk factors.

(2) Generate the direct impact matrix of construction safety risk factors. According to the experience of experts and construction site personnel $k(k=1,2, \ldots, m)$, process the arithmetic mean value to eliminate the subjective error of experts as much as possible; then, obtain the direct impact matrix $X\left(X=\left[x_{i j}\right]_{n * n}\right)$ between factors as follows:

$$
X=\frac{1}{M} \sum_{k=1}^{m} X^{k} \text {. }
$$

(3) Obtain a new normalized impact matrix from the direct impact matrix $G\left(G=\left[g_{i j}\right]_{n * n}\right)$ :

$$
G=\left[g_{i j}\right]_{n \times n}=\frac{1}{\max _{1 \leq 1 \leq n} \sum_{j=1}^{n} r_{i j}} X,
$$

where $\max _{1 \leq 1 \leq n} \sum_{j=1}^{n} r_{i j} A$ is the maximum value obtained by adding each row. After normalized treatment, obtain $0 \leq g_{i j} \leq 1$.

(4) Calculate the comprehensive impact matrix $T\left(T=\left[t_{i j}\right]_{n * n}\right):$

$$
T=G^{1}+G^{2}+\cdots+G^{n}=\sum_{i=1}^{n} G^{i} .
$$

Since $0 \leq g_{i j} \leq 1$, when $n \longrightarrow \infty, G^{n-1} \longrightarrow 0$, the following formula can be used for approximate calculation:

$$
T=G(I-G)^{-1}
$$

(5) Calculate the influencing degree $f_{i}$ and the influenced degree $e_{i}$. The influencing degree $f_{i}$ is obtained by adding the row elements of the matrix $T$, and the influenced $e_{i}$ degree is obtained by adding the column elements of matrix $T$. The calculation formulas for the influencing degree $f_{i}$ and the influenced degree $e_{i}$ are as follows:

$$
\begin{aligned}
f_{i} & =\sum_{j=1}^{n} t_{i j}, \quad i=1, \ldots, n, \\
e_{i} & =\sum_{j=1}^{n} t_{j i}, \quad i=1, \ldots, n .
\end{aligned}
$$

The greater the centrality, the more important the factor.

(6) Calculate centrality and causality. Centrality $m_{i}$ is obtained by adding the influencing degree and the influenced degree of the system, and the causality $n_{i}$ is obtained by subtracting the influencing degree and the influenced degree of the system. The formulas for calculating centrality $m_{i}$ and causation $n_{i}$ are as follows:

$$
\begin{aligned}
m_{i} & =f_{i}+e_{i}, \quad i=1, \ldots, n, \\
n_{i} & =f_{i}-e_{i}, \quad i=1, \ldots, n .
\end{aligned}
$$




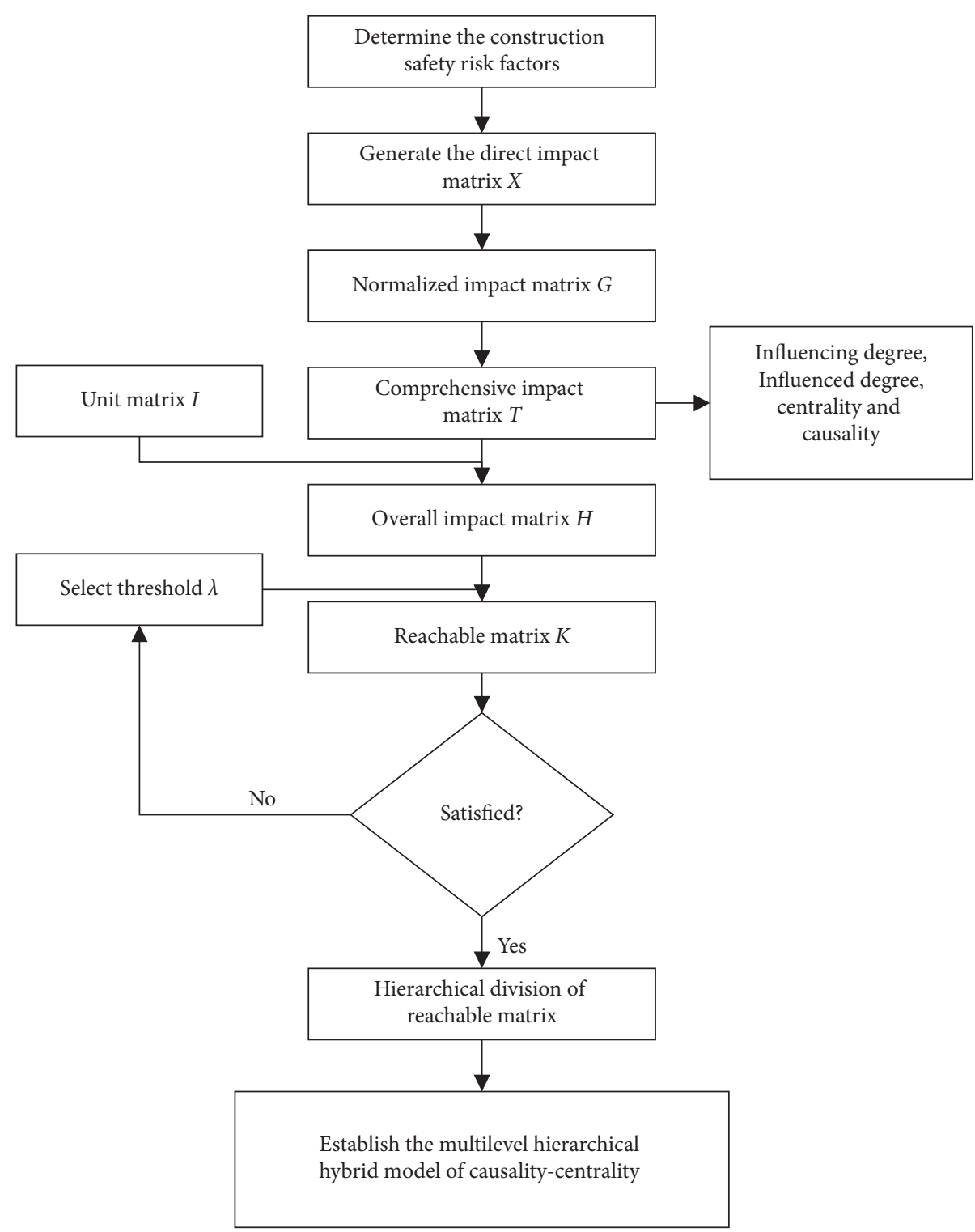

Figure 2: Basic flow of DEMATEL-ISM model.

(7) Establish the causality-centrality diagram of the influence factor, the causality is the ordinate, centrality is the abscissa, and the diagram is drawn on the Cartesian coordinate system.

(8) Calculate the overall impact matrix $H\left(H=\left[h_{i j}\right]_{n * n}\right)$ :

$$
H=I+T,
$$

where $I$ is the identity matrix.

(9) Calculate the reachable matrix, $K\left(K=\left[K_{i j}\right]_{n \times n}\right)$. Given a threshold $\lambda$, calculate the reachable matrix $K\left(K=\left[K_{i j}\right]_{n \times n}\right)$ :

$$
\begin{array}{ll}
k_{i j}=1, & \text { if } h_{i j} \geq \lambda, \quad i, j, 2, \ldots, n, \\
k_{i j}=0, & \text { if } h_{i j}<\lambda, \quad i, j, 2, \ldots, n .
\end{array}
$$

The key to establishing the reachable matrix is to determine the threshold $\lambda$. If the degree of influence of one factor on another factor exceeds $\lambda$, the factor will directly affect the other factor. If the reverse is true, then this factor does not affect the other factor. Since the purpose of the value of $\lambda$ is to highlight the main causes of accidents in the complex system and at the same time not to oversimplify the relationship among the factors, the value is selected multiple times and optimized on the basis of expert suggestions and actual needs.

(10) Determine the reachable set $A_{i}$ and the antecedent set $B_{i}$ of each factor.

(11) Verify that the following formula holds. If so, the corresponding factor is the bottom factor and the $i$ row and $i$ column are crossed out in matrix $K$. 


$$
A_{i}=A_{i} \cap B_{i}, \quad i=1, \ldots, n .
$$

(12) Repeat steps 10 and 11 until all factors are crossed out.

(13) According to the order in which the factors are crossed out, combined with the causality and centrality, the multilevel hierarchical hybrid model of causality-centrality is established.

\section{Case Study and Result Analysis}

3.1. Study Subject and Data Collection. This study takes the Fuyang station of Hanghuang high-speed railway as the subject. Fuyang station is located in Fuyang District, Hangzhou City, Zhejiang Province. The station house has three floors, one underground and two above ground. The underground is reinforced concrete frame structure, and the above-ground part is steel structure. The location of Fuyang station is shown in Figure 3.

The excavation depth of the foundation pit is 6.8 14.4 meters, which is the first level foundation pit. Fuyang District has abundant rainfall and high groundwater level. According to the above-determined construction safety risk factor set, we adopt the method of expert consultation to study the relevant influence relations of the 17 factors that affect construction safety. Twenty-four questionnaires were distributed to professors and associate professors of the

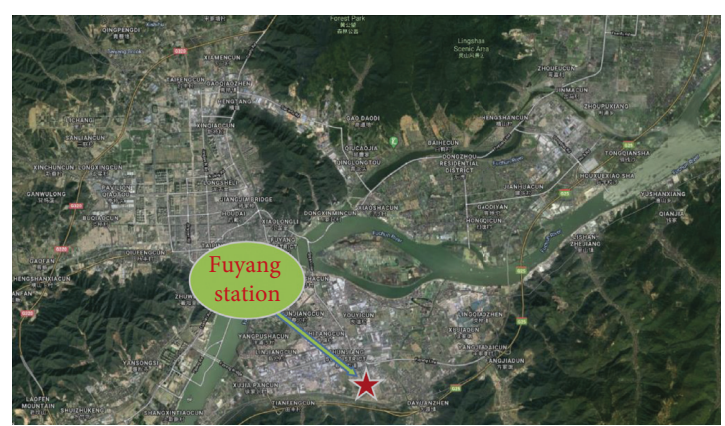

Figure 3: The location of Fuyang station (from Google Maps).

School of Civil Engineering and Architecture of Ningbo Institute of Technology, Zhejiang University, and safety managers of China Railway Fourth Bureau, and twenty-two questionnaires were recovered (the recovery rate was $92 \%$ ). The influence of a factor is represented by a five-point scale, where 0 means no influence, 1 means weak influence, 2 means general influence, 3 means strong influence, and 4 means extremely strong influence.

Arithmetic mean processing of the data in the questionnaire is carried out to eliminate expert error as much as possible, and the direct impact matrix $X=\left[x_{i j}\right]_{17 \times 17}$ is formed:

$$
X=\left[\begin{array}{ccccccccccccccccc}
0 & 1.17 & 3.42 & 2.67 & 2.42 & 1.5 & 1.75 & 1.5 & 0.42 & 0.5 & 1 & 2.5 & 2.5 & 2.67 & 2.75 & 3.25 & 3.08 \\
1.75 & 0 & 2.33 & 1.17 & 1.42 & 0.75 & 0.92 & 0.92 & 0.17 & 0 & 0.5 & 0.75 & 1 & 1.25 & 1.33 & 1.33 & 1.83 \\
0.58 & 0.75 & 0 & 1.75 & 1.58 & 2.42 & 1.75 & 2.5 & 0.08 & 0.71 & 0.92 & 0.75 & 1.67 & 2 & 2 & 2.17 & 2.58 \\
0.17 & 0.33 & 1.02 & 0 & 1.67 & 2.25 & 2.58 & 2.08 & 0 & 0 & 1 & 0.75 & 1.75 & 1.75 & 1.67 & 1.83 & 2.08 \\
0.33 & 0.17 & 1.25 & 1.08 & 0 & 3 & 1.67 & 2.42 & 0 & 0 & 0.25 & 0.58 & 1.17 & 1.25 & 1.25 & 1.42 & 1.75 \\
0.08 & 0.42 & 1.17 & 1 & 1.67 & 0 & 1.17 & 2 & 0 & 0 & 0.42 & 0.42 & 1.17 & 1.25 & 1.67 & 1.92 & 1.83 \\
0.58 & 0.33 & 2 & 1.83 & 1.75 & 2.5 & 0 & 2.08 & 0 & 0 & 1.92 & 1.08 & 1.42 & 1.58 & 1.67 & 1.42 & 1.75 \\
0.17 & 0.58 & 1.58 & 1 & 2 & 2.08 & 1.75 & 0 & 0.33 & 0.33 & 0.75 & 1.17 & 1.75 & 1.92 & 2 & 2.33 & 2 \\
0.33 & 1.17 & 1.42 & 0.92 & 0.92 & 1.92 & 0.67 & 1.75 & 0 & 2.25 & 2.17 & 0.83 & 0.83 & 1.17 & 1.17 & 1.5 & 1.5 \\
0.5 & 0.75 & 1.08 & 1.5 & 1 & 1.5 & 1.25 & 1.58 & 1.42 & 0 & 2.5 & 1.42 & 0.92 & 1.08 & 1.17 & 1.25 & 1.25 \\
1.42 & 1.33 & 2.58 & 2.42 & 0.83 & 1.67 & 2.17 & 1.92 & 0.42 & 0.08 & 0 & 1.67 & 1.08 & 1.75 & 1.58 & 1.92 & 1.75 \\
1.5 & 0.83 & 2.5 & 1.75 & 1.83 & 1.92 & 1.58 & 1.83 & 0.17 & 0 & 0.67 & 0 & 2.25 & 2.42 & 2.67 & 2.58 & 2.67 \\
0.92 & 0.67 & 2.25 & 1.75 & 1.42 & 1.5 & 1.25 & 1.5 & 0.33 & 0.25 & 0.58 & 0.92 & 0 & 2.42 & 2.17 & 2.42 & 2.5 \\
0.67 & 0.83 & 1.5 & 1.92 & 1 & 1.08 & 1.08 & 0.92 & 0 & 0 & 0.17 & 0.5 & 1.17 & 0 & 1.5 & 1.33 & 1.75 \\
1.33 & 0.67 & 2.92 & 1.75 & 1.58 & 1.58 & 1.42 & 1.83 & 0 & 0 & 0.25 & 1.42 & 2 & 2.25 & 0 & 2.33 & 2.42 \\
0.83 & 1.17 & 2.42 & 1.17 & 0.83 & 1.08 & 0.42 & 0.92 & 0 & 0 & 0.25 & 0.58 & 0.75 & 1 & 1.17 & 0 & 2 \\
0.67 & 0.92 & 1.92 & 0.75 & 0.75 & 1.42 & 0.42 & 1 & 0.25 & 0.17 & 0.33 & 0.67 & 1 & 1.17 & 1.33 & 1 & 0
\end{array}\right] .
$$




\subsection{Calculation of the Integrated DEMATEL/ISM Method}

3.2.1. DEMATEL Analysis. According to step 3, normalize the direct influence matrix to obtain the normalized influence matrix $G=\left[g_{i j}\right]_{17 \times 17}$ :

$$
G=\left[\begin{array}{ccccccccccccccccc}
0 & 0.03 & 0.09 & 0.07 & 0.07 & 0.04 & 0.05 & 0.04 & 0.01 & 0.01 & 0.03 & 0.07 & 0.07 & 0.07 & 0.08 & 0.09 & 0.09 \\
0.05 & 0 & 0.06 & 0.03 & 0.04 & 0.02 & 0.03 & 0.03 & 0 & 0 & 0.01 & 0.02 & 0.03 & 0.03 & 0.04 & 0.04 & 0.05 \\
0.02 & 0.02 & 0 & 0.05 & 0.04 & 0.07 & 0.05 & 0.07 & 0 & 0 & 0.03 & 0.02 & 0.05 & 0.06 & 0.06 & 0.06 & 0.07 \\
0 & 0.01 & 0.05 & 0 & 0.05 & 0.06 & 0.07 & 0.06 & 0 & 0 & 0.03 & 0.02 & 0.05 & 0.05 & 0.05 & 0.05 & 0.06 \\
0.01 & 0.01 & 0.03 & 0.03 & 0 & 0.08 & 0.05 & 0.07 & 0 & 0 & 0.01 & 0.02 & 0.03 & 0.03 & 0.03 & 0.04 & 0.05 \\
0 & 0.01 & 0.03 & 0.03 & 0.05 & 0 & 0.03 & 0.06 & 0 & 0 & 0.01 & 0.01 & 0.03 & 0.03 & 0.05 & 0.05 & 0.05 \\
0.02 & 0.01 & 0.06 & 0.05 & 0.05 & 0.07 & 0 & 0.06 & 0 & 0 & 0.05 & 0.03 & 0.04 & 0.04 & 0.05 & 0.04 & 0.05 \\
0 & 0.02 & 0.04 & 0.03 & 0.06 & 0.06 & 0.05 & 0 & 0.01 & 0.01 & 0.02 & 0.03 & 0.05 & 0.05 & 0.06 & 0.06 & 0.06 \\
0.01 & 0.03 & 0.04 & 0.03 & 0.03 & 0.05 & 0.02 & 0.05 & 0 & 0.03 & 0.06 & 0.02 & 0.02 & 0.03 & 0.03 & 0.04 & 0.04 \\
0.01 & 0.02 & 0.03 & 0.04 & 0.03 & 0.04 & 0.03 & 0.04 & 0.04 & 0 & 0.07 & 0.04 & 0.03 & 0.03 & 0.03 & 0.03 & 0.03 \\
0.04 & 0.04 & 0.07 & 0.07 & 0.02 & 0.05 & 0.06 & 0.05 & 0.01 & 0 & 0 & 0.05 & 0.03 & 0.05 & 0.04 & 0.05 & 0.05 \\
0.04 & 0.02 & 0.07 & 0.05 & 0.05 & 0.05 & 0.04 & 0.05 & 0 & 0 & 0.02 & 0 & 0.06 & 0.07 & 0.07 & 0.07 & 0.07 \\
0.03 & 0.02 & 0.06 & 0.05 & 0.04 & 0.04 & 0.03 & 0.04 & 0.01 & 0.01 & 0.02 & 0.03 & 0 & 0.07 & 0.06 & 0.07 & 0.07 \\
0.02 & 0.02 & 0.04 & 0.03 & 0.03 & 0.03 & 0.03 & 0.03 & 0 & 0 & 0 & 0.01 & 0.03 & 0 & 0.04 & 0.04 & 0.05 \\
0.04 & 0.02 & 0.08 & 0.05 & 0.04 & 0.04 & 0.04 & 0.05 & 0 & 0 & 0.01 & 0.04 & 0.06 & 0.06 & 0 & 0.06 & 0.07 \\
0.02 & 0.03 & 0.07 & 0.03 & 0.02 & 0.03 & 0.01 & 0.03 & 0 & 0 & 0.01 & 0.02 & 0.02 & 0.03 & 0.03 & 0 & 0.06 \\
0.02 & 0.03 & 0.05 & 0.02 & 0.02 & 0.04 & 0.01 & 0.03 & 0.01 & 0 & 0.01 & 0.02 & 0.03 & 0.03 & 0.04 & 0.03 & 0
\end{array}\right] .
$$

According to step 4, calculate the comprehensive influence matrix $T=\left[t_{i j}\right]_{17 \times 17}$ :

$$
T=\left[\begin{array}{ccccccccccccccccc}
0.05 & 0.08 & 0.22 & 0.16 & 0.16 & 0.15 & 0.13 & 0.15 & 0.02 & 0.02 & 0.07 & 0.13 & 0.16 & 0.18 & 0.19 & 0.21 & 0.22 \\
0.07 & 0.02 & 0.13 & 0.08 & 0.09 & 0.08 & 0.07 & 0.8 & 0.01 & 0 & 0.03 & 0.05 & 0.08 & 0.09 & 0.09 & 0.1 & 0.12 \\
0.05 & 0.05 & 0.08 & 0.1 & 0.1 & 0.14 & 0.1 & 0.14 & 0.01 & 0.01 & 0.05 & 0.06 & 0.11 & 0.13 & 0.13 & 0.14 & 0.16 \\
0.03 & 0.04 & 0.13 & 0.05 & 0.1 & 0.13 & 0.12 & 0.12 & 0 & 0 & 0.05 & 0.06 & 0.11 & 0.12 & 0.11 & 0.12 & 0.14 \\
0.03 & 0.03 & 0.09 & 0.07 & 0.05 & 0.13 & 0.09 & 0.12 & 0 & 0 & 0.03 & 0.05 & 0.08 & 0.09 & 0.09 & 0.1 & 0.11 \\
0.02 & 0.03 & 0.09 & 0.07 & 0.09 & 0.05 & 0.07 & 0.1 & 0 & 0 & 0.03 & 0.04 & 0.08 & 0.09 & 0.1 & 0.11 & 0.11 \\
0.05 & 0.04 & 0.13 & 0.11 & 0.11 & 0.14 & 0.06 & 0.12 & 0.01 & 0 & 0.08 & 0.07 & 0.10 & 0.11 & 0.12 & 0.14 & 0.13 \\
0.03 & 0.04 & 0.12 & 0.08 & 0.11 & 0.13 & 0.1 & 0.07 & 0.01 & 0.01 & 0.05 & 0.07 & 0.11 & 0.12 & 0.12 & 0.14 & 0.14 \\
0.04 & 0.06 & 0.11 & 0.08 & 0.08 & 0.12 & 0.07 & 0.11 & 0.01 & 0.07 & 0.09 & 0.06 & 0.08 & 0.09 & 0.1 & 0.11 & 0.12 \\
0.04 & 0.05 & 0.1 & 0.09 & 0.08 & 0.11 & 0.09 & 0.11 & 0.04 & 0.01 & 0.09 & 0.08 & 0.08 & 0.09 & 0.1 & 0.11 & 0.11 \\
0.07 & 0.07 & 0.16 & 0.13 & 0.09 & 0.13 & 0.12 & 0.13 & 0.02 & 0.01 & 0.03 & 0.09 & 0.1 & 0.13 & 0.13 & 0.14 & 0.15 \\
0.08 & 0.06 & 0.17 & 0.12 & 0.12 & 0.14 & 0.11 & 0.13 & 0.01 & 0.01 & 0.05 & 0.05 & 0.14 & 0.16 & 0.16 & 0.17 & 0.18 \\
0.06 & 0.05 & 0.14 & 0.1 & 0.1 & 0.11 & 0.09 & 0.11 & 0.01 & 0.01 & 0.04 & 0.07 & 0.06 & 0.14 & 0.13 & 0.14 & 0.15 \\
0.04 & 0.04 & 0.1 & 0.06 & 0.07 & 0.08 & 0.07 & 0.07 & 0 & 0 & 0.02 & 0.04 & 0.07 & 0.05 & 0.09 & 0.09 & 0.11 \\
0.07 & 0.05 & 0.17 & 0.11 & 0.11 & 0.12 & 0.1 & 0.12 & 0.01 & 0.01 & 0.04 & 0.08 & 0.12 & 0.14 & 0.08 & 0.15 & 0.16 \\
0.04 & 0.05 & 0.12 & 0.07 & 0.06 & 0.08 & 0.05 & 0.07 & 0 & 0 & 0.02 & 0.04 & 0.06 & 0.08 & 0.08 & 0.05 & 0.11 \\
0.04 & 0.04 & 0.1 & 0.06 & 0.06 & 0.08 & 0.05 & 0.07 & 0.01 & 0.01 & 0.03 & 0.04 & 0.07 & 0.08 & 0.08 & 0.08 & 0.05
\end{array}\right] .
$$


Calculate the influencing degree, influenced degree, centrality, and causality, as shown in Table 2.

As shown in Table 2, influencing factors can be divided into reason factors and result factors according to the centrality (centrality greater than 0 is reason factors, while centrality less than 0 is result factors). Centrality determines the importance of the factor in the system. To visualise the degree of influence of factors, establish the quartile of the influence factor, and use the centrality and causality of the factor as Cartesian coordinates, as shown in Figure 4. The detailed analysis is in Section 3.3.

3.2.2. ISM Analysis. According to step 9, select multiple thresholds $\lambda$ for comparative analysis, as listed in Table 3 .

Finally, determine the selected threshold, $\lambda=0.11$, and convert the specification influence matrix $G$ into the reachable matrix $K=\left[k_{i j}\right]_{17 \times 17}$ by MATLAB programming.

$$
K=\left[\begin{array}{lllllllllllllllll}
1 & 0 & 1 & 1 & 1 & 1 & 1 & 1 & 0 & 0 & 0 & 1 & 1 & 1 & 1 & 1 & 1 \\
0 & 1 & 1 & 0 & 0 & 1 & 0 & 1 & 0 & 0 & 0 & 0 & 1 & 1 & 1 & 1 & 1 \\
0 & 0 & 1 & 0 & 0 & 1 & 0 & 1 & 0 & 0 & 0 & 0 & 1 & 1 & 1 & 1 & 1 \\
0 & 0 & 1 & 1 & 0 & 1 & 1 & 1 & 0 & 0 & 0 & 0 & 1 & 1 & 1 & 1 & 1 \\
0 & 0 & 1 & 0 & 1 & 1 & 0 & 1 & 0 & 0 & 0 & 0 & 1 & 1 & 1 & 1 & 1 \\
0 & 0 & 0 & 0 & 0 & 1 & 0 & 0 & 0 & 0 & 0 & 0 & 0 & 0 & 0 & 0 & 1 \\
0 & 0 & 1 & 0 & 0 & 1 & 11 & 1 & 0 & 0 & 0 & 0 & 1 & 1 & 1 & 1 & 1 \\
0 & 0 & 1 & 0 & 0 & 1 & 0 & 1 & 0 & 0 & 0 & 0 & 1 & 1 & 1 & 1 & 1 \\
0 & 0 & 1 & 0 & 0 & 1 & 0 & 1 & 1 & 0 & 0 & 0 & 1 & 1 & 1 & 1 & 1 \\
0 & 0 & 0 & 0 & 0 & 0 & 0 & 0 & 0 & 1 & 0 & 0 & 0 & 0 & 0 & 0 & 1 \\
0 & 0 & 1 & 1 & 0 & 1 & 1 & 1 & 0 & 0 & 1 & 0 & 1 & 1 & 1 & 1 & 1 \\
0 & 0 & 1 & 1 & 1 & 1 & 1 & 1 & 0 & 0 & 0 & 1 & 1 & 1 & 1 & 1 & 1 \\
0 & 0 & 1 & 0 & 0 & 1 & 0 & 1 & 0 & 0 & 0 & 0 & 1 & 1 & 1 & 1 & 1 \\
0 & 0 & 0 & 0 & 0 & 0 & 0 & 0 & 0 & 0 & 0 & 0 & 0 & 1 & 0 & 0 & 0 \\
0 & 0 & 1 & 0 & 0 & 1 & 0 & 1 & 0 & 0 & 0 & 0 & 1 & 1 & 1 & 1 & 1 \\
0 & 0 & 1 & 0 & 0 & 1 & 0 & 1 & 0 & 0 & 0 & 0 & 1 & 1 & 1 & 1 & 1 \\
0 & 0 & 0 & 0 & 0 & 0 & 0 & 0 & 0 & 0 & 0 & 0 & 0 & 0 & 0 & 0 & 1
\end{array}\right] .
$$

According to steps 9-11, process the reachable matrix, and, finally, obtain the factor set $C q(q=1,2, \ldots, n)$ of each layer. Finally, establish the multilevel hierarchical hybrid model, as shown in Figure 5.

3.3. Construction Safety Risk Factors and Related Influence Mechanisms. According to the DEMATEL analysis, the factors can be divided into cause factors and result factors. In the actual construction process, more attention should be paid to the causes, and effective control should be carried out to improve the safety of the construction site. As Table 2 shows, the influencing degree of these factors varies greatly, ranging from 0.98 to 2.435 .
The eight factors with high impact include cognitive defects R1, imperfect safety management systems R12, complex construction site environments R11, inadequate supervision of safety behaviours R15, illegal operations R3, inadequate safety disclosure R13, numerous large-scale equipment cross-operations R7, and failure of construction monitoring equipment R8. Therefore, management factors and human factors can be classified as factors that potentially affect construction safety by influencing other factors. The influenced degree indicates the comprehensive influence of other factors on the factor Ri. At the level of impact, errors in construction safety operational guidelines R17, illegal operations R3, inadequate safety protection measures R16, mechanical failure R6, inadequate supervision of safety behaviours R15, inadequate acceptance of key processes R14, failure of construction monitoring equipment R8, and inadequate safety disclosure R13 are the leaders, which shows that the security level can be improved by increasing influencers. Inadequate supervision of safety behaviours $\mathrm{R} 15$, inadequate safety disclosure R13, and failure of construction monitoring equipment R8 are all important influencing factors and affected factors; improving these factors will help improve the circulatory effects in the system.

Centrality reflects the importance of factors in the system. As shown in Table 2, illegal operations R3 is the most important, followed by inadequate supervision of safety behaviours R15, failure of construction monitoring equipment R8, errors in construction safety operational guidelines $\mathrm{R} 17$, inadequate safety disclosure R13, cognitive defects R1, inadequate safety protective measures R16, mechanical equipment failure R6, imperfect safety management systems $\mathrm{R} 12$, unreasonable equipment selection and layout R4, multiple cross-operations of large equipment R7, inadequate acceptance of key processes R14, lack of maintenance and repair of equipment $\mathrm{R} 5$, construction site complex environment R11, poor physical or mental health status R2, complex hydrogeological environments R10, and unforeseen natural factors R9. Among all the factors, illegal operations R3, inadequate supervision of safety behaviours $\mathrm{R} 15$, failure of construction monitoring equipment R8, errors in construction safety operational guidelines R17, inadequate safety disclosure R13, cognitive defects R1, inadequate safety protection measures R16, mechanical failure R6, and imperfect safety management systems R12 are especially important. However, complex construction site environment R11, poor physical or mental health R2, complex hydrogeological environments R10, and unforeseen natural factors R9 also play important roles that cannot be ignored. Safety issues must be analysed from a systematic perspective. In the human-machine-environmental-management system, management factors closely related to people are the most important factors affecting construction safety.

In the multilevel hierarchical hybrid model, cognitive defects R1, imperfect safety management systems R12, and complex construction site environments R11 are deep factors, and unforeseeable natural factors R9, numerous largescale equipment cross-operations R7, lack of maintenance 
TABLE 2: DEMATEL parameter table.

\begin{tabular}{|c|c|c|c|c|c|c|}
\hline Factor & Influencing degree & Influenced degree & Centrality & Causality & Centrality ranking & Factor attribute \\
\hline R1 & 2.435 & 0.868 & 3.303 & 1.567 & 6 & Reason factor \\
\hline $\mathrm{R} 2$ & 1.267 & 0.855 & 2.122 & 0.412 & 15 & Reason factor \\
\hline $\mathrm{R} 3$ & 1.613 & 2.317 & 3.929 & -0.704 & 1 & Result factor \\
\hline $\mathrm{R} 4$ & 1.512 & 1.629 & 3.141 & -0.117 & 10 & Result factor \\
\hline R5 & 1.194 & 1.669 & 2.862 & -0.475 & 14 & Result factor \\
\hline R6 & 1.140 & 2.043 & 3.183 & -0.902 & 8 & Result factor \\
\hline R7 & 1.546 & 1.580 & 3.126 & -0.034 & 11 & Result factor \\
\hline $\mathrm{R} 8$ & 1.516 & 1.926 & 3.442 & -0.410 & 3 & Result factor \\
\hline R9 & 1.421 & 0.191 & 1.612 & 1.230 & 17 & Reason factor \\
\hline $\mathrm{R} 10$ & 1.440 & 0.186 & 1.626 & 1.253 & 16 & Reason factor \\
\hline R11 & 1.798 & 0.832 & 2.630 & 0.966 & 14 & Reason factor \\
\hline $\mathrm{R} 12$ & 1.977 & 1.170 & 3.147 & 0.807 & 9 & Reason factor \\
\hline R13 & 1.600 & 1.729 & 3.330 & -0.129 & 5 & Result factor \\
\hline R14 & 1.061 & 2.029 & 3.090 & -0.968 & 12 & Result factor \\
\hline R15 & 1.691 & 2.032 & 3.723 & -0.341 & 2 & Result factor \\
\hline R16 & 1.047 & 2.218 & 3.265 & -1.171 & 7 & Result factor \\
\hline $\mathrm{R} 17$ & 0.980 & 2.419 & 3.399 & -1.438 & 4 & Result factor \\
\hline
\end{tabular}

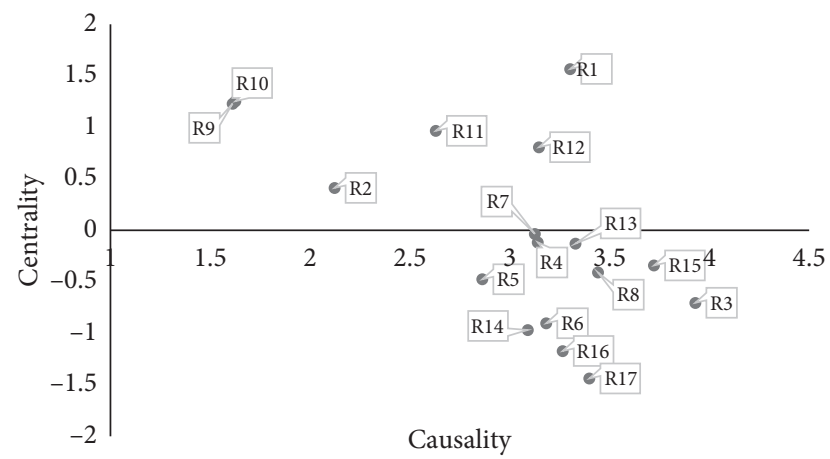

Figure 4: Causal diagram of influencing factors of construction safety risk.

TABLE 3: Comparison of different threshold $\lambda$.

\begin{tabular}{lcccc}
\hline Factor & 0.09 & 0.1 & 0.11 & 0.15 \\
\hline R1 & 13 & 13 & 13 & 10 \\
R2 & 5 & 3 & 2 & 0 \\
R3 & 27 & 24 & 18 & 5 \\
R4 & 18 & 17 & 11 & 1 \\
R5 & 15 & 11 & 5 & 1 \\
R6 & 18 & 16 & 13 & 1 \\
R7 & 19 & 14 & 11 & 0 \\
R8 & 22 & 21 & 15 & 0 \\
R9 & 7 & 5 & 3 & 0 \\
R10 & 9 & 5 & 1 & 0 \\
R11 & 14 & 10 & 9 & 1 \\
R12 & 15 & 13 & 13 & 5 \\
R13 & 19 & 16 & 10 & 2 \\
R14 & 15 & 11 & 10 & 3 \\
R15 & 23 & 18 & 16 & 5 \\
R16 & 17 & 16 & 12 & 3 \\
R1 & 18 & 18 & 16 & 6 \\
\hline
\end{tabular}

and overhaul of equipment R5, inadequate supervision of safety behaviours R15, unreasonable equipment selection and layout R4, and poor physical or mental health R2 are middle factors. Mechanical failure R6, errors in construction safety operational guidelines R17, complex hydrogeological environments R10, inadequate acceptance of key processes R14, failure of construction monitoring equipment R8, inadequate safety disclosure R13, inadequate safety protection measures R16, and illegal operations R3 are surface factors.

Human-related factors, such as cognitive deficits R1, are deep factors; illegal operations R3 ranks second in centrality; and poor physical or mental health R2 belongs to the middle factors. These findings show that human-related factors play a pivotal role in construction safety risks and must be taken seriously. Factors related to management, such as imperfect safety management systems R12, are surface factors, and poor supervision of safety behaviours R15, inadequate safety disclosure R13, and inadequate safety protection measures R16 are ranked 2nd, 5th, and 7th in centrality, respectively. The system has an important impact.

According to Figure 5, the key factors are cognitive defects R1, illegal operations R3, failure of construction monitoring equipment R8, imperfect safety management systems R12, inadequate safety disclosures R13, and inadequate supervision of safety behaviours R15. However, in the multilevel hierarchical hybrid model, key factors exist in the three-layer structure, which indicates that, in security risk control, we must not only pay attention to the proximal causes but also comprehensively consider the overall perspective. In addition, except for the failure of construction monitoring equipment, all the factors are related to the human or management aspects.

As the above analysis shows, the human and management aspects need to focus on control. In addition, the following corresponding measures are proposed:

(1) Strengthen safety education. Personnel training and education can be provided through multimedia resources such as Virtual Reality (VR) equipment and on-site teaching simultaneously. On-site self-help and self-protection training should be conducted. 


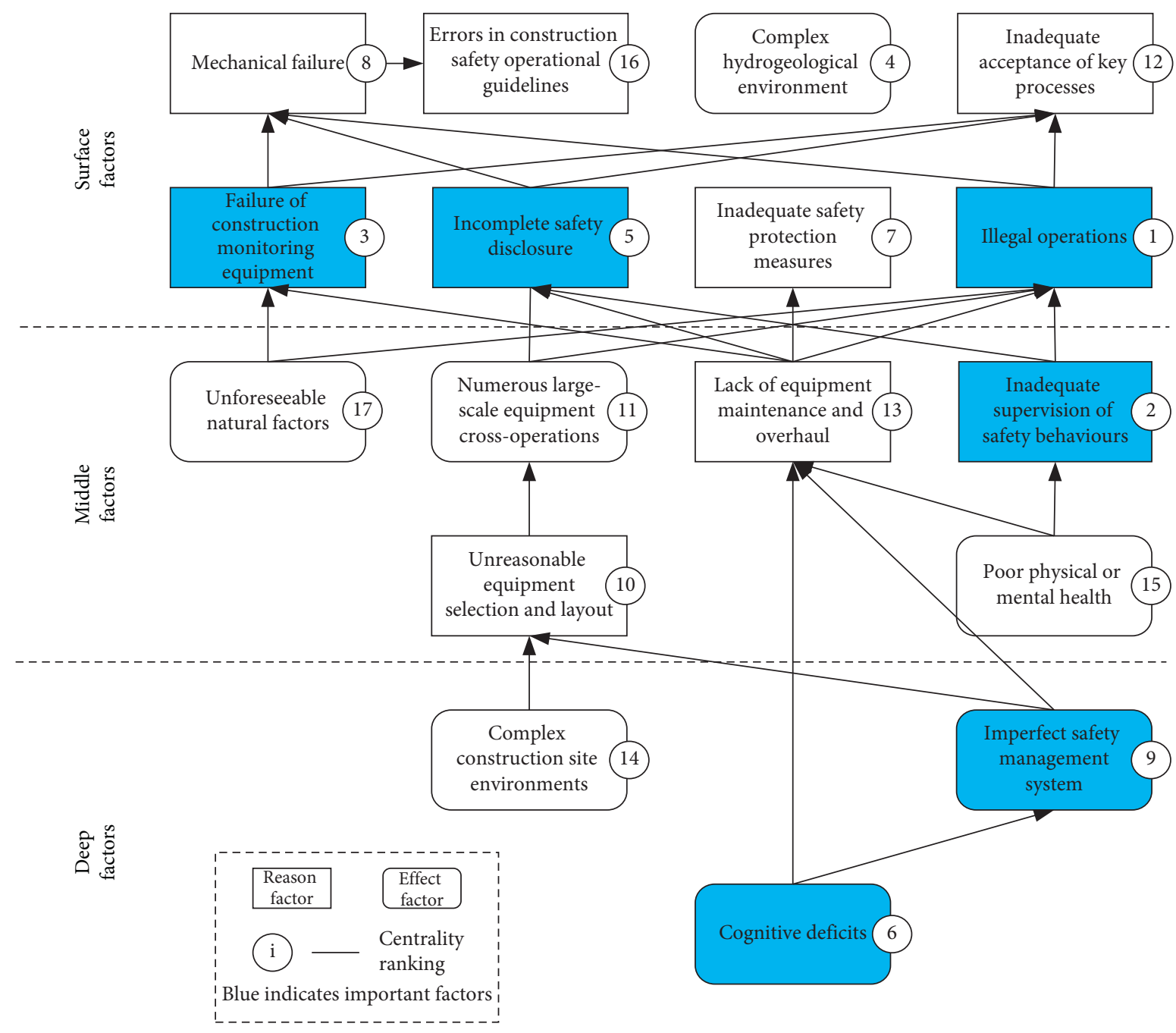

FIGURE 5: Multilevel hierarchical hybrid model.

(2) Improve safety and protection measures. Safety protection measures should be taken for major hazards to avoid safety accidents.

(3) Scientifically arrange the construction sequence to reduce environmental uncertainty.

(4) Improve rules and regulations. Enterprises should improve the responsibility system for production safety and establish various rules and regulations for safety inspection and on-site management.

(5) Focus on the production management of key processes, master the construction status in advance, eliminate safety hazards, and formulate effective preventive measures.

(6) Develop a special safety plan. It is necessary to combine the characteristics of the project to prepare specialized, targeted, and operable special safety programmes and technical measures.

(7) Strengthen the implementation of safety supervision. Strengthen the enforcement capacity of safety supervision, and timely discover to solve safety problems in production.
(8) Master professional skills and knowledge. Ensure that workers master relevant practices. Check for related knowledge and skills, reward and update them, and retest regularly.

(9) Perform good safety technical clarification. The construction technology department and the safety risk management agency should cooperate to implement construction safety.

\section{Conclusion}

Construction accidents in high-speed railway station construction are the result of the joint actions of humans, machines, the environment, and management. Based on system safety theory, an index system of the influencing factors of construction safety is established with humanmachine-environment management aspects, and the influencing mechanism among the influencing factors is analysed. The main conclusions are as follows:

(1) DEMATEL and ISM can be combined to analyse the relationship among various factors affecting 
construction safety. DEMATEL is used to analyse the centrality and causation of construction safety risk factors and to determine the key factors. According to the results, causation was divided into 6 causes and 11 results. ISM is used to divide construction safety risk factors into three hierarchical structures and to obtain a multilevel hierarchical hybrid model of influencing factors.

(2) The conclusion is that personnel factors and management factors need to be controlled with emphasis. Three main factors, six important factors, and seven direct factors are obtained by analyzing the risk factors affecting the construction safety of highspeed railway station.

(3) The factors that affect the construction safety of highspeed railway stations are extraordinarily complex and have classification modes. In security risk control, we should not only pay attention to the proximal cause but also start from the overall situation and consider all factors comprehensively.

\section{Data Availability}

The data used to support the findings of this study are included within the article.

\section{Conflicts of Interest}

The authors declare that there are no conflicts of interest regarding the publication of this paper.

\section{Acknowledgments}

The authors acknowledge the financial support of Science and Technology Project of Ningbo Transportation Bureau (Grant no. 202007) and Science and Technology Research and Development Project of China Railway Construction Group Co., Ltd. (2020-12).

\section{References}

[1] J. Zhang and J. Zhang, "Comprehensive evaluation of operating speeds for high-speed railway: a case study of China high-speed railway," Mathematical Problems in Engineering, vol. 2021, Article ID 8826193, 16 pages, 2021.

[2] General Office of the Ministry of Housing and Urban-Rural Development, Circular of the General Office of the Ministry of Housing and Urban-Rural Development on the Special Action to Address Production Safety Accidents and Construction Safety in Housing and Municipal Projects in 2018General Office of the Ministry of Housing and Urban-Rural Development, Beijing, China, 2019.

[3] BLS, "Injuries, illnesses, and fatalities," 2021, http://www. mohurd.gov.cn/wjfb/201903/t20190326_239913.html.

[4] Health and Safety Executive, "Workplace fatal injuries in Great Britain," 2020, https:/www.hse.gov.uk/statistics/.

[5] E. C. Wigglesworth, "Human factors in level crossing accidents," Accident Analysis \& Prevention, vol. 10, no. 3, pp. 229-240, 1978.
[6] A. Lawrence, "Human error as a cause of accidents in gold mining," Journal of Safety Research, vol. 6, no. 2, pp. 78-88, 1974.

[7] H. W. Heinrich, Industrial Accident Prevention. A Scientific Approach, Industrial Accident Prevention. A Scientific Approach., McGraw-Hill Education, New York, NY, USA, 2nd edition, 1941.

[8] W. Haddon Jr., "The changing approach to the epidemiology, prevention, and amelioration of trauma: the transition to approaches etiologically rather than descriptively based," American Journal of Public Health and the Nations Health, vol. 58, no. 8, pp. 1431-1438, 1968.

[9] W. Haddon Jr., "A logical framework for categorizing highway safety phenomena and activity," The Journal of Trauma: Injury, Infection, and Critical Care, vol. 12, no. 3, pp. 193-207, 1972.

[10] F. P. McKenna, "Accident proneness: a conceptual analysis," Accident Analysis \& Prevention, vol. 15, no. 1, pp. 65-71, 1983.

[11] N. G. Leveson, "A new approach to hazard analysis for complex systems," in Proceedings of the 2003 International Conference of the System Safety Society, Ottawa, Canada, 2003.

[12] E. Hollnagel and O. Goteman, "The functional resonance accident model," Proceedings of Cognitive System Engineering in Process Plant, vol. 2004, pp. 155-161, 2004.

[13] Z. Guo, L. Chen, K. Yin, D. P. Shrestha, and L. Zhang, "Quantitative risk assessment of slow-moving landslides from the viewpoint of decision-making: a case study of the Three Gorges reservoir in China," Engineering Geology, vol. 273, Article ID 105667, 2020.

[14] M. O. Sanni-Anibire, A. S. Mahmoud, M. A. Hassanain, and B. A. Salami, "A risk assessment approach for enhancing construction safety performance," Safety science, vol. 121, pp. 15-29, 2020.

[15] M. R. Hallowell and J. A. Gambatese, "Qualitative research: application of the Delphi method to CEM research," Journal of Construction Engineering and Management, vol. 136, no. 1, pp. 99-107, 2010.

[16] O. Rozenfeld, R. Sacks, Y. Rosenfeld, and H. Baum, "Construction job safety analysis," Safety science, vol. 48, no. 4, pp. 491-498, 2010.

[17] E. E. Ameyaw, Y. Hu, M. Shan, A. P. C. Chan, and Y. Le, "Application of Delphi method in construction engineering and management research: a quantitative perspective," Journal of Civil Engineering and Management, vol. 22, no. 8, pp. 991-1000, 2016.

[18] K. Alomari, J. Gambatese, C. Nnaji, and N. Tymvios, "Impact of risk factors on construction worker safety: a Delphi rating study based on field worker perspective," Arabian Journal for Science and Engineering, vol. 45, no. 10, pp. 8041-8051, 2020.

[19] G. Zhang, C. Wang, Y Jiao et al., "Collapse risk analysis of deep foundation pits in metro stations using a fuzzy Bayesian network and a fuzzy AHP," Mathematical Problems in Engineering, vol. 2020, Article ID 4214379, 18 pages, 2020.

[20] D. A. Patel and K. N. Jha, "Evaluation of construction projects based on the safe work behavior of co-employees through a neural network model," Safety Science, vol. 89, pp. 240-248, 2016.

[21] W. Z. Taffese and E. Sistonen, "Neural network based hygrothermal prediction for deterioration risk analysis of surface-protected concrete façade element," Construction and Building Materials, vol. 113, pp. 34-48, 2016.

[22] Y. Kim and S. S. Lee, "Application of artificial neural networks in assessing mining subsidence risk," Applied Sciences, vol. 10, no. 4, p. 1302, 2020. 
[23] A. Nieto-Morote and F. Ruz-Vila, "A fuzzy approach to construction project risk assessment," International Journal of Project Management, vol. 29, no. 2, pp. 220-231, 2011.

[24] W. Zhang, B. Li, Z. Liu, and B. Zhang, "Application of improved fuzzy comprehensive evaluation method in karst groundwater quality evaluation: a case study of Cengong county," Earth Science Informatics, vol. 14, pp. 1101-1109, 2021.

[25] Z. Guo, K. Yin, F. Huang, S. Fu, and W. Zhen, "Evaluation of landslide susceptibility based on landslide classification and weighted frequency ratio model," Chinese Journal of Rock Mechanics and Engineering, vol. 38, no. 2, pp. 287-300, 2019.

[26] A. Rice, The Enterprise and Its Environment, Routledge, London, UK, 1991.

[27] S. Bertelsen, "Construction as a complex system," in Proceedings for the 11th Annual Conference of the International Group for Lean Construction, Blacksburg, VA, USA, 2003.

[28] N. Leveson, "A new accident model for engineering safer systems," Safety Science, vol. 42, no. 4, pp. 237-270, 2004.

[29] J. Rasmussen, "Risk management in a dynamic society: a modelling problem," Safety Science, vol. 27, no. 2, pp. 183-213, 1997.

[30] D. q. Zhou, L. Zhang, and H.-w. Li, “A study of the system's hierarchical structure through integration of DEMATEL and ISM," in Proceedings of the 2006 International Conference on Machine Learning and Cybernetics, IEEE, Dalian, China, 2006.

[31] Q. Zhou, W. Huang, and Y. Zhang, "Identifying critical success factors in emergency management using a fuzzy DEMATEL method," Safety Science, vol. 49, no. 2, pp. 243-252, 2011.

[32] A. Medina-Borja and K. S. Pasupathy, "Uncovering complex relationships in system dynamics modeling: Exploring the use of CART, CHAID and SEM," in Proceedings of the 25th International Conference of the System Dynamics Society, pp. 1-24, Boston, MA, USA, 2007.

[33] T. L. Saaty, "Making and validating complex decisions with the AHP/ANP," Journal of Systems Science and Systems Engineering, vol. 14, no. 1, pp. 1-36, 2005.

[34] C. Zhou, L. Y. Ding, M. J. Skibniewski, H. Luo, and H. T. Zhang, "Data based complex network modeling and analysis of shield tunneling performance in metro construction," Advanced Engineering Informatics, vol. 38, pp. 168-186, 2018.

[35] S. Ahmed, "Causes of accident at construction sites in Bangladesh," Organization, Technology and Management in Construction: An International Journal, vol. 11, no. 1, pp. 1933-1951, 2019.

[36] R. A. Haslam, S. A. Hide, A. G. F. Gibb et al., "Contributing factors in construction accidents," Applied ergonomics, vol. 36, no. 4, pp. 401-415, 2005.

[37] L. Wang, Q. Cao, and L. Zhou, "Research on the influencing factors in coal mine production safety based on the combination of DEMATEL and ISM," Safety Science, vol. 103, pp. 51-61, 2018.

[38] W. Du, G. Jing, and Q. Shi, "Preliminary study on safety analysis of man-machine-environment system in underground transportation," Chinese Journal of Safety Science, vol. 3, pp. 37-40, 1997.

[39] J. Zhang, K. Xu, G. You et al., "Causation analysis of risk coupling of gas explosion accident in chinese underground coal mines," Risk Analysis, vol. 39, no. 7, pp. 1634-1646, 2019.

[40] H. Kim, H. S. Lee, M. Park et al., "Influence factor-based safety risk assessment methodology for construction site," in Proceedings of the Construction Research Congress 2010:
Innovation for Reshaping Construction Practice, Banff, Canada, 2010.

[41] W. Qiao, "Analysis and measurement of multifactor risk in underground coal mine accidents based on coupling theory," Reliability Engineering \& System Safety, vol. 208, Article ID 107433, 2021.

[42] C. M. Tam, S. X. Zeng, and Z. M. Deng, "Identifying elements of poor construction safety management in China," Safety Science, vol. 42, no. 7, pp. 569-586, 2004.

[43] Z. Ding, M. Zhu, V. W. Y. Tam, G. Yi, and C. N. N. Tran, "A system dynamics-based environmental benefit assessment model of construction waste reduction management at the design and construction stages," Journal of Cleaner Production, vol. 176, pp. 676-692, 2018.

[44] S.-B. Tsai, J. Zhou, Y. Gao et al., "Combining FMEA with DEMATEL models to solve production process problems," PLoS One, vol. 12, no. 8, Article ID e0183634, 2017.

[45] S. Tong, J. Liu, L. Zhao et al., "Impact on water traffic environment based on ISM model," in Proceedings of the 2019 5th International Conference on Transportation Information and Safety (ICTIS), IEEE, Liverpool, UK, 2019. 